\title{
TEMPERAMENTAL CORRELATES OF TRAUMA SYMPTOMS IN FIREMEN, POLICEMEN AND SOLDIERS
}

\section{WŁODZIMIERZ ONISZCZENKO}

University of Warsaw, Warszawa, Poland

Faculty of Psychology, Department of Psychology of Individual Differences

\begin{abstract}
Objectives: The main goal of the research was to assess temperamental determinants of trauma symptoms in firemen, policemen and soldiers. The temperament traits which were considered were those postulated by the Regulative Theory of Temperament (briskness, perseveration, sensory sensitivity, emotional reactivity, endurance and activity). Material and Methods: A cross-sectional study was run on non-clinical samples. The participants were 417 men, White-Caucasian only: 284 firemen (aged 21-55), 58 policemen (aged 22-45), and 75 soldiers (aged 21-42). Temperament was assessed using the Formal Characteristics of Behavior - Temperament Inventory. Intensity of trauma symptoms was assessed with the PTSD-Factorial Version Inventory, a quantitative measure of trauma-related symptoms. The respondents were examined in their place of work. The study included only men reporting at least 1 traumatic event during the year before the trauma diagnosis. Results: Emotional reactivity had a significant positive effect on the intensity of trauma symptoms only in the group of firemen. Emotional reactivity accounted for $16 \%$ of the variance of trauma intensity symptoms in this occupational group. Negative significant effect on trauma symptoms was found for briskness only in the soldiers group (briskness explained 20\% trauma intensity variance in this group). Conclusions: Emotional reactivity was conducive to the increased trauma symptoms intensity in firemen, whereas briskness tended to reduce symptoms intensity only in the group of soldiers.
\end{abstract}

Key words:

Trauma, Temperament, Firemen, Policemen, Soldiers

\section{INTRODUCTION}

This is a study of the intensity of trauma symptoms (assessed psychometrically, not clinically) in individuals engaged in emergency-services and soldiers involved in military operations.

Research findings suggest that firemen, policemen and soldiers experience many potentially traumatic events and that some of them develop anxiety disorders, including post-traumatic stress disorder (PTSD) [1]. It is also known that various psychological and physical factors play a significant role in the aetiology of trauma-related symptoms in these 3 occupational groups. These factors are, for example, burns and physical injuries, fire incidents with multiple deaths, motor vehicle accidents involving multiple deaths, suicides and others that may concern firemen and policemen [2,3]. On the other hand, combat experiences, number of times in combat, amputations, traumatic brain injuries, blast-related traumatic brain injuries and others are identified as factors affecting the symptoms of

This study was funded by grant No. 1445-02-2009 from the University of Warsaw, Poland. Manager of grant: Włodzimierz Oniszczenko, Prof. Received: November 3, 2013. Accepted: May 2, 2014.

Corresponding author: W. Oniszczenko, Faculty of Psychology, Department of Psychology of Individual Differences, University of Warsaw, Stawki 5-7, 00-183 Warszawa, Poland (e-mail: wlodek@psych.uw.edu.pl). 
trauma in soldiers exposed to both, physical and emotional trauma in combat zones [4-7].

Some researchers suggest that temperament traits can play a significant role in responses to trauma both in emergency-services professionals as well as in soldiers. Most indicate that neuroticism and negative emotionality intensify symptoms of trauma [8-10], and extroversion and sensation seeking are buffers for its development [11-14]. The Regulative Theory of Temperament (RTT) [15] also emphasizes the role of temperament in human responses to stressful situations. Temperament traits can be observed in all human behaviours and in all situations, especially those highly arousing ones. The reason why these traits are important is that we are born with our temperaments and therefore, their underlying biological mechanisms help to regulate individual levels of arousal.

The structure of temperament is assumed to consist of 6 temperamental traits [16]:

- Briskness (BR) - defined as a tendency to react quickly, to maintain a high tempo in performing activities and to shift easily from one behavior (reaction) to another in response to changes in the surroundings.

- Perseveration (PE) - a tendency to continue and repeat behavior and to experience emotional states after cessation of the stimuli (situations) that evoke this behavior or these states.

- Sensory sensitivity (SS) - understood as an ability to react to sensory stimuli of low stimulative value.

- Emotional reactivity (ER) - a tendency to react intensively to emotion-generating stimuli expressed in high emotional sensitivity and low emotional endurance.

- Endurance (EN) - defined as ability to react adequately in situations demanding long-lasting or highly stimulative activity and/or under-intensive external stimulation.

- Activity (AC) - a tendency to undertake behaviors of a high stimulative value or to provide, by means of behavior, strong stimulation from the surroundings.
Emotional reactivity shows significant phenotypic and genetic links to neuroticism, while BR, EN and AC are phenotypically and genetically correlated with extraversion, as described in the 5-factor theory $[17,18]$.

Taking the PTSD theoretical construct and its DSM-IV definition [19], we distinguished, using a factor analysis, 2 basic trauma symptoms: intrusion/arousal (I/A) and avoidance/numbing $(\mathrm{A} / \mathrm{N})$. The 1st symptom involves recurrent thoughts (flashbacks) about the traumatic event, which are a source of intensive psycho-physiological arousal, while the 2nd symptom involves avoidance of trauma-related stimuli and diminished reactions to these stimuli [20].

The results of our previous studies showed that ER and PE intensified trauma symptoms in a group of disaster victims [21], in cancer patients [22] and in HIV+ individuals [23]. Both traits, ER and PE, were also positively correlated with somatic anxiety in students [24]. Emotional reactivity was also positively correlated, whereas BR was negatively correlated, with trauma symptoms in motor vehicle accident survivors [25]. Three other temperament traits i.e., BR, EN and AC are usually negatively correlated with the severity of trauma symptoms and likely act as resources that protect individuals against the risk of PTSD (the role of SS is unclear).

Based on the data from the literature concerning the role of neuroticism and extraversion in trauma development, and taking account of the RTT assumptions, we expected that a high level of trauma symptoms would be associated with high levels of ER and PE. We also supposed that BR, EN and $\mathrm{AC}$ would act as buffers to protect against the development of trauma in firemen, policemen and soldiers.

\section{MATERIAL AND METHODS}

\section{Participants}

The participants from non-clinical samples were 417 men, only White-Caucasians, including 284 firemen aged 21-55 years $($ mean $(\mathrm{M})=33.96$; standard deviation 
$(\mathrm{SD})=7.18), 58$ policemen aged $22-45$ years $(\mathrm{M}=33.78$; $\mathrm{SD}=5.26)$ from a criminal investigation unit and 75 soldiers aged 21-42 years $(\mathrm{M}=29.08 ; \mathrm{SD}=4.11)$ involved in military operations in Afghanistan. The respondents were examined in their place of work.

The participants were recruited through direct contact with fire brigades, a criminal investigation police unit as well as with a military unit. The firemen reported participation in actions aiming at rescuing victims of traffic accidents, policemen reported contact with dead victims of various accidents and soldiers participated in combat mission patrols. All groups had experienced at least one traumatic event during the year before the trauma diagnosis. The data were collected between 2009 and 2012. The study was anonymous and participation was voluntary. The participants were not paid.

\section{Measures}

Temperament traits were measured with the FCB-TI [26]. This questionnaire has 120 items, 20 items per scale, in a yes/no response format. The FCB-TI consists of the following scales (Cronbach's $\alpha$ are given in parentheses): briskness (0.77), perseveration (0.79), sensory sensitivity $(0.73)$, emotional reactivity $(0.83)$, endurance $(0.85)$ and activity (0.84). Test-retest stability scores ranged from 0.69 (briskness) to 0.90 (activity).

The quantitative level of trauma symptoms was assessed using the PTSD-Factorial Version (PTSDF) inventory containing 30 items. Each item is rated on a 4-point scale where 1 means that a symptom is absent and 4 means that it is always present. This questionnaire has 2 subscales: intrusion/arousal (I/A) (Cronbach's $\alpha=0.96)$ and avoidance/numbing (A/N) (Cronbach's $\alpha=0.92)$. Both factors - I/A and A/N - are highly correlated with each other [20]. The scores on each subscale were added to calculate the general intensity of trauma symptoms (general scale: Cronbach's $\alpha=0.96)$. All analyses in the reported studies were based on the total score of the PTSDF inventory, well reflecting the intensity of trauma symptoms. The validity of this scale was confirmed by correlating it with other clinical constructs and with the civilian version of the Mississippi PTSD [20].

\section{Ethical approval}

The research project was accepted by the Ethics Commission at the Faculty of Psychology, University of Warsaw, Poland.

\section{Statistical analysis}

Statistical analysis was performed by the use of IBM SPSS Statistics 21 [27]. The differences between groups were tested using 1-way ANOVA. Correlations between the variables were identified using Pearson product moment correlation coefficients. The validity of temperament traits as predictors of trauma intensity was estimated using hierarchical regression analysis.

\section{RESULTS}

The basic descriptive statistics and significance test outcomes for differences between the studied groups are presented in Table 1.

Scheffe's post-hoc test revealed a number of significant differences between the groups. A significant difference in the age between the firemen group as well as police officers group compared to the soldiers $(p=0.000)$ was shown, but no differences in the age between the firemen and police officers were reported.

The firemen had significantly higher levels of BR compared to the soldiers $(p=0.005)$ and lower levels compared to the police officers $(p=0.000)$. They also had higher levels of $\mathrm{PE}$ in comparison with the police officers ( $p=0.003$ ), lower levels of SS compared to the police officers $(p=0.000)$ and soldiers $(p=0.000)$, higher levels of ER compared to the police officers ( $p=0.034$ ), as well as lower levels of EN compared to the police officers 
Table 1. Means and standard deviations comparisons for age and temperament traits and trauma symptoms in the groups of firefighters, policemen and soldiers

\begin{tabular}{|c|c|c|c|c|c|}
\hline Variable & $\begin{array}{c}\text { Firefighters } \\
(\mathrm{N}=284) \\
\mathrm{M} \pm \mathrm{SD}\end{array}$ & $\begin{array}{c}\text { Policemen } \\
(\mathrm{N}=58) \\
\mathrm{M} \pm \mathrm{SD}\end{array}$ & $\begin{array}{c}\text { Soldiers } \\
(\mathrm{N}=75) \\
\mathrm{M} \pm \mathrm{SD}\end{array}$ & $\mathrm{F}$ & $\mathrm{p}$ \\
\hline Age & $33.96 \pm 7.18$ & $33.78 \pm 5.26$ & $29.08 \pm 4.11$ & 17.21 & 0.000 \\
\hline \multicolumn{6}{|l|}{ Temperament traits } \\
\hline briskness & $16.65 \pm 3.03$ & $20.19 \pm 6.59$ & $15.00 \pm 3.78$ & 30.91 & 0.000 \\
\hline perseveration & $9.18 \pm 4.64$ & $7.00 \pm 4.08$ & $7.91 \pm 3.88$ & 7.09 & 0.001 \\
\hline sensory sensitivity & $9.13 \pm 1.88$ & $14.97 \pm 3.49$ & $13.88 \pm 3.56$ & 196.91 & 0.000 \\
\hline emotional reactivity & $6.21 \pm 4.34$ & $4.57 \pm 4.68$ & $5.48 \pm 4.27$ & 3.74 & 0.025 \\
\hline endurance & $10.15 \pm 1.75$ & $14.03 \pm 5.32$ & $13.85 \pm 4.43$ & 68.23 & 0.000 \\
\hline activity & $11.51 \pm 4.29$ & $10.12 \pm 4.72$ & $13.09 \pm 3.67$ & 8.20 & 0.000 \\
\hline \multicolumn{6}{|l|}{ PTSDF scales } \\
\hline intrusion/arousal & $23.04 \pm 6.46$ & $21.16 \pm 5.48$ & $27.19 \pm 9.75$ & 14.09 & 0.000 \\
\hline avoidance/numbing & $19.67 \pm 4.92$ & $20.09 \pm 4.91$ & $27.05 \pm 10.24$ & 42.74 & 0.000 \\
\hline global score & $42.70 \pm 10.30$ & $41.24 \pm 9.74$ & $54.33 \pm 19.32$ & 28.81 & 0.000 \\
\hline
\end{tabular}

PTSDF - PTSD-Factorial Version.

$\mathrm{M}$ - mean; SD - standard deviation.

$\mathrm{df}=2.416$.

$(\mathrm{p}=0.000)$ and soldiers $(\mathrm{p}=0.000)$ and lower levels of AC compared to the soldiers ( $\mathrm{p}=0.017$ ).

The policemen, compared to the soldiers, had significantly higher levels of BR $(p=0.000)$ and SS $(p=0.049)$ and lower levels of $\mathrm{AC}(\mathrm{p}=0.000)$. No significant differences were found in the other temperament traits between the groups. The highest level of trauma symptoms was observed in the group of soldiers. It was significantly higher in comparison with the firemen $(p=0.000)$ and policemen $(p=0.000)$. The soldiers also had a significantly higher level of intrusion/arousal $(p=0.000)$ and avoidance/numbing $(\mathrm{p}=0.000)$ compared to the firemen and policemen. No significant difference in trauma symptoms between the firemen and police officers was shown.

The results of the correlation analysis are shown in Table 2.

Table 2. Pearson-r correlations between age and temperament traits and trauma symptoms in the study groups $(\mathrm{N}=417)$

\begin{tabular}{lccc}
\hline \multicolumn{1}{c}{ Variable } & Intrusion/arousal & Avoidance/numbing & Global scale \\
\hline Age & 0.03 & -0.02 & 0.01 \\
Briskness & $-0.29^{* * *}$ & $-0.31^{* * *}$ & $-0.32^{* * *}$ \\
Perseveration & $0.36^{* * *}$ & $0.17^{* *}$ & $0.28^{* * *}$ \\
Sensory sensitivity & -0.06 & 0.04 & -0.01 \\
Emotional reactivity & $0.38^{* * *}$ & $0.32^{* * *}$ & $0.38^{* * *}$ \\
Endurance & $-0.16^{* *}$ & -0.03 & $-0.10^{*}$ \\
Activity & $-0.12^{*}$ & $-0.15^{* *}$ & $-0.14^{* *}$ \\
\hline
\end{tabular}

${ }^{*} \mathrm{p}<0.05 ; * * \mathrm{p}<0.01 ; * * * \mathrm{p}<0.000$. 
All trauma symptoms correlated negatively with BR, EN and AC and positively with PE and ER. There was a lack of correlation with SS. There was also no correlation with age.

In order to determine the extent to which specific temperament traits can be viewed as predictors of trauma symptoms or protective buffers, a hierarchical regression analysis was conducted in all the respondents. The variables, which were most strongly correlated with the PTSDF global score were accepted as possible predictors of trauma symptoms or protective buffers in the three study groups. The results are presented in Table 3.

Emotional reactivity was a significant predictor of intensity of trauma symptoms in the firemen group only. This trait accounted for $16 \%$ of the variance in the firemen group. Briskness explained $20 \%$ of intensity of trauma symptoms only in 1 group, i.e. soldiers. PE as a temperament trait was not critical for predicting the intensity of trauma symptoms in either studied group.

Table 3. Hierarchical regression analyses with selected temperament traits as predictors of trauma symptoms separately for each of the study group

\begin{tabular}{|c|c|c|c|c|c|c|}
\hline Model & $\mathrm{F}$ & $\mathrm{F} \Delta \mathrm{R}^{2}$ & $\mathrm{R}$ & $\mathrm{R}^{2}$ & Predictor & $\begin{array}{c}\text { Semi-partial } \\
\text { correlation }\end{array}$ \\
\hline \multicolumn{7}{|l|}{ Firemen } \\
\hline ER & $56.98^{\mathrm{a}, * * *}$ & - & 0.41 & 0.16 & ER & $0.41^{* * *}$ \\
\hline \multirow[t]{2}{*}{$+\mathrm{PE}$} & $29.98^{\mathrm{b}, * * *}$ & 2.65 & 0.42 & 0.17 & ER & $0.26^{* * *}$ \\
\hline & & & & & $\mathrm{PE}$ & 0.09 \\
\hline \multirow[t]{3}{*}{$+\mathrm{BR}$} & $20.86^{\mathrm{c}}, * * *$ & 2.34 & 0.43 & 0.17 & ER & $0.21^{* * *}$ \\
\hline & & & & & PE & 0.09 \\
\hline & & & & & $\mathrm{BR}$ & -0.08 \\
\hline \multicolumn{7}{|l|}{ Policemen } \\
\hline ER & $6.30^{c, *}$ & - & 0.32 & 0.08 & ER & $0.32^{*}$ \\
\hline \multirow[t]{2}{*}{$+\mathrm{PE}$} & $4.71^{\mathrm{e}, *}$ & 2.90 & 0.38 & 0.11 & ER & 0.12 \\
\hline & & & & & PE & 0.21 \\
\hline \multirow[t]{3}{*}{$+\mathrm{BR}$} & $3.97^{\mathrm{f}, *}$ & 2.27 & 0.42 & 0.13 & ER & 0.17 \\
\hline & & & & & $\mathrm{PE}$ & 0.18 \\
\hline & & & & & $\mathrm{BR}$ & 0.19 \\
\hline \multicolumn{7}{|l|}{ Soldiers } \\
\hline ER & $30.18^{\mathrm{g}, * * *}$ & _ & 0.54 & 0.28 & ER & $0.54^{* * *}$ \\
\hline \multirow[t]{2}{*}{$+\mathrm{PE}$} & $14.90^{\mathrm{h}, * * *}$ & 0.02 & 0.54 & 0.27 & ER & $0.37^{* * *}$ \\
\hline & & & & & PE & 0.02 \\
\hline \multirow[t]{3}{*}{$+B R$} & $22.91^{\mathrm{i}, * * *}$ & $27.83^{* * *}$ & 0.70 & 0.47 & ER & 0.08 \\
\hline & & & & & PE & 0.07 \\
\hline & & & & & $\mathrm{BR}$ & $-0.45^{* * *}$ \\
\hline
\end{tabular}

ER - emotional reactivity; PE - perseveration; BR - briskness.

${ }^{\mathrm{a}} \mathrm{df}=1,282 ;{ }^{\mathrm{b}} \mathrm{df}=2,281 ;{ }^{\mathrm{c}} \mathrm{df}=3,280 ;{ }^{\mathrm{d}} \mathrm{df}=1,56 ;{ }^{\mathrm{e}} \mathrm{df}=2,55 ;{ }^{\mathrm{f}} \mathrm{df}=3,54 ;{ }^{\mathrm{g}} \mathrm{df}=1,73 ;{ }^{\mathrm{h}} \mathrm{df}=2,72 ;{ }^{\mathrm{i}} \mathrm{df}=3,71$.

$* \mathrm{p}<0.05 ; * * \mathrm{p}<0.001$. 


\section{DISCUSSION}

The results of our earlier studies [22,23,25] suggested that tendency for strong emotional reactions fosters development of trauma symptoms. Therefore, we expected that emotional reactivity, as the trait associated with neuroticism is important for increasing trauma symptoms, not only in clinical groups (cancer patients or HIV+ people) but also in professional groups.

The results of our current study partially confirmed the importance of ER for intensity of trauma symptoms. However, regardless of other traits, ER explains some of the trauma symptoms variance, but among other predictors, its importance is significantly reduced. Only in the group of firemen ER proved to be a significant predictor of trauma symptoms, explaining $16 \%$ of the variance of trauma intensity symptoms. It is also worth noting that the firemen, compared to the police officers, had higher levels of ER and a low level of BR. Despite these differences in temperament, there was no significant difference in the severity of trauma among the firemen and policemen. Both groups are exposed to similar sources of emotional trauma, such as contact with corpses. Psychological significance of these sources may be similar in both groups.

Despite the differences in the temperament traits between the firemen and policemen, traumatic factors are probably not strong enough to cause various symptoms of trauma among these groups (like frequent and immediate life threats, as in the case of soldiers). Although we cannot rule out possible future consequences of firemen and police officers' jobs on their health, this hypothesis would require longitudinal studies.

In the group of policemen ER itself explains a small part of trauma symptoms, but when we added the 2 other traits: BR and PE to the analysis, the importance of all 3 traits has decreased to a negligible level. Most likely in this group, other factors, such as coping strategies or other personality traits play an important role.
The most interesting result obtained in this study was indication that BR may serve as a protective buffer against intensification of trauma symptoms. In this study, BR served this role only in the group of soldiers. Briskness explained $20 \%$ of the variability of trauma symptoms in this group.

It should be noted that the group with the highest severity of trauma was the group of soldiers exposed to particularly strong physical and psychological trauma in combat zones and the lowest level of BR was also observed in the group of soldiers. Strong traumatic experiences and lowlevel BR as a protective buffer may likely intensify the severity of trauma in a group of soldiers. Additionally, they showed not more ER compared to the firemen and policemen. Soldiers were the youngest group, but age was not related to trauma symptoms (Table 2). It seems that the main source of the high level of trauma in the group was the experience of combat trauma and other uncontrollable factors, such as emotional ambivalence (EA), i.e. the occurrence of conflicting emotions towards a specific object. In young soldiers, EA may be related to curiosity about war and at the same time the fear of death or mutilation. Other studies have shown that EA coincides with posttraumatic stress in military personnel [28]. In this context, low BR, unfavourable for fast adaptation, may be an additional risk factor for soldiers' trauma development.

Although SS levels were not related to the severity of trauma in the study groups, it is worth noting that its highest level was seen in the groups of police officers and soldiers and their lowest level in the group of firemen. In our earlier study [23], a low level of SS was associated with trauma resulting from stigma associated with HIV + . In the case of police officers and soldiers, high levels of SS may be due to the specificity of their investigative work (police) or long-term stays in military camps (soldiers). Reduced social stimulation in both groups may lead to an increase in SS. This change may confirm 
the compensatory role of temperament. In conclusion, the lack of significance of perseveration for the development of trauma symptoms in the 3 studied groups, unlike the clinical groups we studied earlier, is worth noting. It appears that specific, well-organised professional activity of the studied groups modifies and/or potentially limits the persistence of emotional reactions, contrary to the people suffering from chronic, long-lasting disease with uncertainty about development and consequences of the disease.

The present study was not free from certain limitations. The study groups, due to the number of participants and the manner of their selection, were not representative of their professions. They did not have the same number of participants, and we did not control a number of other important factors such as demographic variables, health problems, coping with stress and social support as important variables. Nevertheless, the results indicate the need for good counselling organisations for all the study groups, with a particular emphasis on soldiers.

\section{CONCLUSIONS}

The highest level of trauma symptoms was observed in the soldiers with experience of military operations. Emotional reactivity was conducive to the increased trauma symptoms intensity in the firemen, whereas BR tended to reduce symptoms intensity only in the soldiers. It seems that BR, ER, and PE are negligible for trauma symptoms in the group of policemen.

\section{ACKNOWLEDGEMENTS}

I would like to express my gratitude for Marta Szcześnik, MA, from the Main School of Fire Service, Warszawa, Poland, and Monika Moczarska, MA, from the University of Finance and Management, Warszawa, Poland, who took part in collecting the data.

\section{REFERENCES}

1. Adler AB, Keane TM, Bliese PD. Measurement of posttraumatic stress disorder in an occupational health context. In: Sinclair RR, Wang M, Tetrick LE, editors. Research methods in occupational health psychology: Measurement, design, and data analysis. New York: Routledge / Taylor \& Francis Group; 2013. p. 122-37.

2. Corneil W, Beaton R, Murphy S, Johnson C, Pike K. Exposure to traumatic incidents and prevalence of posttraumatic stress symptomatology in urban firefighters in two countries. J Occup Health Psychol. 1999;4(2):131-41, http://dx.doi. org/10.1037/1076-8998.4.2.131.

3. Wagner S, McFee JA, Martin CA. Mental health implications of fire service membership. Traumatology. 2010;16(2):26-32, http://dx.doi.org/10.1177/1534765610362803.

4. Osório C, Greenberg N, Jones N, Goodwin L, Fertout M, Maia Â. Combat exposure and posttraumatic stress disorder among Portuguese special operation forces deployed in Afghanistan. Mil Psychol. 2013;25(1):70-81, http://dx.doi. org/10.1037/h0094758.

5. Ragsdale KA, Neer SM, Beidel DC, Frueh BC, Stout JW. Posttraumatic stress disorder in OEF/OIF veterans with and without traumatic brain injury. J Anxiety Disord. 2013;27: 420-6, http://dx.doi.org/10.1016/j.janxdis.2013.04.003.

6. Rigg JL. Traumatic brain injury and post-traumatic stress: The "signature wounds" of the Iraq and Afghanistan wars. In: Scurfield RM, Platoni KT, editors. War trauma and its wake: Expanding the circle of healing. Routledge psychosocial stress series. New York: Routledge / Taylor \& Francis Group; 2013. p. 113-33.

7. Bandelow B, Koch M, Zimmermann P, Biesold K-H, Wedekind D, Falkai P. Posttraumatic stress disorder (PTSD) in the German Armed Forces: A retrospective study in inpatients of a German army hospital. Eur Arch Psychiatry Clin Neurosci. 2012;262(6):459-67, http://dx.doi.org/10.1007/ s00406-012-0289-8.

8. Pineles SL, Rasmusson AM, Yehuda R, Lasko NB, Macklin ML, Pitman RK, et al. Predicting emotional responses to 
potentially traumatic events from pre-exposure waking cortisol levels: A longitudinal study of police and firefighters. Anxiety Stress Coping. 2013;26(3):241-53, http://dx.doi.org/ 10.1080/10615806.2012.672976.

9. Kehle SM, Ferrier-Auerbach AG, Meis LA, Arbisi PA, Erbes CR, Polusny MA. Predictors of postdeployment alcohol use disorders in National Guard soldiers deployed to Operation Iraqi Freedom. Psychol Addict Behav. 2012; 26(1):42-50, http://dx.doi.org/10.1037/a0024663.

10. Peng AC, Riolli LT, Schaubroeck J, Spain ESP. A moderated mediation test of personality, coping, and health among deployed soldiers. J Organ Behav. 2012;33(4):512-30, http:// dx.doi.org/10.1002/job.766.

11. Salters-Pedneault K, Ruef AM, Orr SP. Personality and psychophysiological profiles of police officer and firefighter recruits. Pers Ind Differ. 2010;49(3):210-5, http://dx.doi. org/10.1016/j.paid.2010.03.037.

12. Wagner SL, Martin CA, McFee JA. Investigating the "rescue personality". Traumatology. 2009;15(3):5-12, http://dx.doi. org $/ 10.1177 / 1534765609338499$.

13. Rydstedt LW, Österberg J. Psychological characteristics of Swedish mandatory enlisted soldiers volunteering and not volunteering for international missions: An exploratory study. Psychol Rep. 2013;112(2):678-88, http://dx.doi. org/10.2466/17.02.PR0.112.2.678-688.

14. Parmak M, Mylle JJC, Euwema MC. Personality and the perception of situation structure in a military environment: Seeking sensation versus structure as a soldier. J Appl Soc Psychol. 2013;43(5):1040-9, http://dx.doi.org/10.1111/jasp.12067.

15. Strelau J. Temperament as a regulator of behavior. After fifty years of research. New York: Eliot Werner Publications, Inc.; 2008.

16. Strelau J. The regulative theory of temperament: Current status. Pers Ind Differ. 1996;20(2):131-42, http://dx.doi. org/10.1016/0191-8869(95)00159-X.

17. Kandler C, Held L, Kroll C, Bergeler A, Riemann R, Angleitner A. Genetic links between temperamental traits of the regulative theory of temperament and the Big Five: A mul- titrait-multimethod twin study. J Ind Differ. 2012;33(4): 197-204, http://dx.doi.org/10.1027/1614-0001/a000068.

18. Strelau J, Zawadzki B. Fearfulness and anxiety in research on temperament: Temperamental traits are related to anxiety disorders. Pers Ind Differ. 2011;50(7):907-15, http:// dx.doi.org/10.1016/j.paid.2010.07.008.

19. American Psychiatric Association. Diagnostic and statistical manual of mental disorders. 4th ed. Washington: American Psychiatric Association; 1994.

20. Strelau J, Zawadzki B, Oniszczenko W, Sobolewski A. [The factorial version of the PTSD Inventory (PTSD-F): The development of a questionnaire aimed at assessing basic dimensions of posttraumatic stress disorder]. Przegl Psychol. 2002;45(2):149-76. Polish.

21. Strelau J, Zawadzki B. Trauma and temperament as predictors of intensity of Posttraumatic Stress Disorder symptoms after disaster. Eur Psychol. 2005;10(2):124-35, http://dx.doi. org/10.1027/1016-9040.10.2.124.

22. Oniszczenko W, Laskowska A. Emotional reactivity, coping style and cancer trauma symptoms. Arch Med Sci. 2014;10(1):110-6, http://dx.doi.org/10.5114/aoms. 2013.33069.

23. Rzeszutek M, Oniszczenko W, Firląg-Burkacka E. Temperament traits, coping style and trauma symptoms in HIV+ men and women. AIDS Care. 2012;24(9):1150-4, http://dx.doi.org/10.1080/09540121.2012.687819.

24. Fruehstorfer DB, Veronie L, Cremeans-Smith JK, Newberry BH. Predicting illness-related outcomes with the FCB-TI trait pairs: Examining the nonadditive effects of FCB-TI perseveration. J Ind Differ. 2012;33(4):248-56, http://dx.doi.org/10.1027/1614-0001/a000070.

25. Zawadzki B, Popiel A. Temperamental traits and severity of PTSD symptoms: Data from longitudinal studies of motor vehicle accident survivors. J Ind Differ. 2012;33(4):257-67, http://dx.doi.org/10.1027/1614-0001/a000074.

26. Strelau J, Zawadzki B. The formal characteristics of behavior - temperament inventory (FCB-TI): Validity studies. Eur J Pers. 1995;9(3):207-29. 
27. IBM Corp. IBM SPSS Statistics 21 core system user's guide. Somers, New York: IBM Corp.; 2012.

28. Jerg-Bretzke L, Walter S, Limbrecht-Ecklundt K, Traue HC.

Emotional ambivalence and post-traumatic stress disorder
(PTSD) in soldiers during military operations. GMS Psycho-Soc-Med. 2013;10:Doc03, http://dx.doi.org/10.3205/psm 000093.

This work is available in Open Access model and licensed under a Creative Commons Attribution-NonCommercial 3.0 Poland License - http://creativecommons.org/ licenses/by-nc/3.0/pl/deed.en. 